J. KSIAM Vol.16, No.4, 257-257, 2012

(Retraction Notice)

\title{
RETRACTION NOTICE TO "THE RELATIONSHIP BETWEEN NONCOMMUTATIVE AND LORENTZVIOLATING PARAMETERS IN \\ QUANTUM" [ J.KSIAM VOL.16, NO.3, 205-216, 2012 ]
}

\author{
A. HEIDARI, F. GHORBANI AND M. GHORBANI*
}

INSTITUTE FOR ADVANCED STUDIES, TEHRAN 14456-63543, IRAN

This article has been retracted at the request of the authors and the Editor-in-Chief.

Reason:

This article has been retracted, please see Journal of Korean Society of Industrial and Applied Mathematics on Article Withdrawal:

http://www.ksiam.org

This article has been retracted at the request of the editor as the authors have plagiarized part of a paper that had already appeared in the Iranian Journal of Physics Research:

http://ijpr.iut.ac.ir/browse.php?a_code=A-10-1-526\&slc_lang=fa\&sid=1

One of the conditions of submission of a paper for publication is that authors declare explicitly that their work is original and has not appeared in a publication elsewhere. Re-use of any data should be appropriately cited. As such this article represents a severe abuse of the scientific publishing system. The scientific community takes a very strong view on this matter and we apologize to readers of the journal that this was not detected during the submission process.

\footnotetext{
${ }^{*}$ Corresponding author.
} 